https://doi.org/10.31713/m1105

\title{
INVESTING THE CAUSES AND EFFECTS OF MINING INDUCED SUBSIDENCE DUE TO SINK HOLES ON THE SOUTH AND EASTERN LIMB AT LUBAMBE MINE, ZAMBIA
}

\author{
Victor Mutambo \\ University of Zambia, School of Mines, Department \\ of Mining Engineering, $\mathrm{PhD}$, Senior Lecturer and Researcher, Zambia
}

Draida Mikoloni

University of Zambia, School of Mines, Department of Mining Engineering, Research Scholar, Mining Engineer, Zambia

\begin{abstract}
Lubambe copper mine is an underground operation with a thin orebody of width ranging between approximately 5-5.5m. Between May 2020 and 2021 the mine experienced a total of six sink holes which were all sudden without giving prior indication of subsidence. The mining subsidence has led to increased mining cost and cycle times due to the closure of $182 \mathrm{ml}$ decline on the eastern limb and $175 \mathrm{ml}$ truck route on the southern limb and disturbance on surface infrastructure.

The main purpose of this study is to investigate the causes and effects of sinkholes on mining operations and surface infrastructure.

Geotechnical empirical and numerical analysis of the ground, core logging, review of rock mass characterisation and evaluation of mining practices were undertaken. The mapping data was analysed using dips, Unwedge and RS3 software.

It has been established that the east limb sinkholes were developed after a catastrophic failure at R3. $82 \mathrm{~mL}$ decline which affected a lateral stretch of approximately $50 \mathrm{~m}$. The first sinkhole on the southern limb was developed after a blast at Ramp 2.325 $\mathrm{mL}$ tips and the second was formed after a fall of ground at Ramp $2.372 \mathrm{ml}$. Empirical analysis for rock mass classification using the Q-system and RQD showed that the ground condition on the south and east limbs were poor to fair.

The sinkholes development on surface are as a result of the sill pillar failures from historical and current mining operations cascading from one level to another and creating hanging wall instability as the ground unravels to fill the voids.

Key words: sinkholes, mining induced subsidence, geotechnical assessment, mining practices

Corresponding author: vmutambo@unza.zm

\section{Introduction}

Lubambe Copper Mine is an underground mining operation situated on the Zambian Copperbelt close to the town of Chililabombwe. The Mine has been in operation since 2012. Between May 2020 and
\end{abstract}


2021 the mine experienced development of a total of six sink holes in a space of one year [1]. All six occurrences were sudden and gave no indication of subsidence in the affected areas. The only indication of subsidence formed on the eastern limb were tension cracks that formed directly above ramp 4. The first occurrence was on the eastern limb where three sinkholes developed after a catastrophic failure on Ramp 3_182 mL decline. The sinkholes formed were trough like with a conical shape, the sinkholes formed on the southern limb occurred a month apart with the first occurrence being in April, second in May and the third in October of 2021.

An empirical post stope stability analysis was conducted and a surface hazard map was developed for physical monitoring of the surface infrastructure placed in close proximity to the caving area. Other methods of monitoring employed were photogrammetry/drone technology, physical inspections and satellite monitoring.

The unexpected development of mining induced subsidence at the mine increased the costs and disrupted production by increasing the cycle times due to the closure of $182 \mathrm{ml}$ decline on the eastern limb and $175 \mathrm{ml}$ truck route on the southern limb. The additional rehabilitation cost on the two excavations was not budgeted for including the six sinkholes which have been successfully backfilled. Rehabilitation of $182 \mathrm{ml}$ decline is still underway from 2020 while $175 \mathrm{ml}$ truck route rehabilitation commenced in November 2021 on the southern limb and has since been completed.

On surface, the sinkholes on the southern limb damaged the main tarred road which was the main access to the mine and nearby community Konkola Township. Furthermore, damages resulting from subsidence led to water disruption to the mine site and community in Konkola Township following the main supply pipes ran along the road that subsidised.

\section{Ground deformation monitoring}

Ground subsidence is the lowering or collapse of the land surface, and is caused by a number of natural and human-induced activities. Natural subsidence occurs when the ground collapses into underground cavities produced by the solution of limestone or other soluble materials by groundwater. Most current subsidence in the corridor is human induced.

Factors effecting Subsidence include [2] 
Depth of Cover,

Overlying Strata Properties,

Seam Thickness,

Panel Width,

Chain Pillar Size

Surface Topography

The need of subsidence monitoring in underground mining is multi-fold:

Legislation,

Subsidence Prediction,

Maximise Ore Extraction,

Structural Design,

Risk Management, and

Environmental Monitoring

Therefore, ground subsidence due to underground mining is of major concern for the mining industry, mining communities and other stakeholders. Subsidence is currently monitored by repeated ground survey using automatic/digital levels (in line levelling), total stations (in EDM height traversing) and GPS receivers (in static and real-time-kinematic (RTK) survey) [3]. Both digital level and total station can deliver $0.1 \mathrm{~mm}$ height change resolution while GPS $5 \mathrm{~mm}$ in static and $2-3 \mathrm{~cm}$ in RTK. On the other hand, the differential radar interferometry (D-InSAR) can deliver approximately $1 \mathrm{~cm}$ height change resolution. Since radar beam scans in range direction, the movement of the platform in azimuth direction completes the 2D imaging of the mining region. The current geodetic technologies can only measure subsidence on a point-by-point basis. Therefore, $D$ InSAR and current geodetic technologies are complementary in monitoring ground subsidence due to underground mining.

Ground subsidence can damage mine and community infrastructure including water resources. Real-time monitoring of ground movements in mining areas can provide early warning of the above problems, which can effectively reduce the occurrence of environmental geological disasters, or at least reduce their impact [4]. The Interferometric Synthetic Aperture Radar (InSAR) is a non-contact and green monitoring technology that has the advantage of being available all day and in any weather conditions. It is characterized by continuous spatial coverage, high automation and high precision. It has become one of the most rapidly developing and potential tech- 
niques for earth observation and mapping. In 1990 s, Camec et al. applied D-InSAR technology to the ground deformation monitoring of mining areas, and verified its feasibility for the first time [5]. Since then, the use of InSAR to monitor ground deformations of mining areas has been rapidly expanding, and important research results have been achieved [6], [7]. For areas with complex terrain or excessive deformation gradients, the interference fringes will be very dense. Coupled with the influence of decorrelation phenomenon, the fringe aliasing phenomenon may occur. All of the above reasons can lead to incorrect unwrapping results or even unwrapping failures, and the quality of unwrapping results directly affects the accuracy of the measurement [8]. Sub-band InSAR, which is a derivative of conventional differential InSAR (D-InSAR), was first proposed by Madsen and Zebker [9], [10]. Its principle is to increase the effective wavelength by several tens or even hundreds of times by reducing the image bandwidth. As a result, the number of interference fringes is correspondingly reduced, and the difficulty of unwrapping is reduced as well. A lot of underground mining activities occur beneath farmland area or forested region; subsequently, temporal decorrelation will make great difficulties for InSAR. Both InSAR and sub-band InSAR rely on interferometric phases to extracting deformations, thus they are usually unable to correctly map the ground deformations characterized by large magnitudes and steep gradients associated with underground mining. The offset-tracking technology is able to extract deformations based on SAR image intensity information, and is not affected by phase noise and deformation gradients. It is mostly used for monitoring of large-scale deformations, such as those related to earthquakes [11], [12], and [13].

Monitoring of large-scale deformation using sub-band InSAR

The large scale and rapid land subsidence that occurs in mining areas leads to problems, such as densely spaced interference fringes and the temporal decorrelation of interferometric synthetic aperture radar (InSAR) interferograms. All, four different bandwidth images with three sub-band bandwidth parameters are used to extract simulated mining induced subsidence with seven different deformation magnitudes. In monitoring subsidence with different deformation magnitudes using images with different bandwidths.an optimal monitoring value exists; wider image bandwidths lead to smaller optimal monitoring values and higher monitoring accuracies. Therefore, an 
appropriate sub-band bandwidth should be selected that depends upon the image bandwidth and the subsidence level to achieve optimal monitoring. The optimal sub-band width for monitoring different magnitudes in mining areas is determined through simulation experiments, and these conclusions can provide a technical basis for selecting the appropriate sub-band bandwidth for monitoring of subsidence in mining areas. Although sub-band InSAR can reduce the number of interference fringes and the difficulty of unwrapping, the simultaneous introduction of large amounts of noise leads to reduced monitoring precision, and the application of the probability integral method in the prediction of mine subsidence is more mature. The probability integral method is used to perform noise peeling on the interferometric phases of the sub-bands to improve the monitoring accuracy of sub-band interferometry.

\section{Rock Quality Designation (RQD)}

$\mathrm{RQD}$ is a measure of the degree of fracturing of the rock mass and is aimed to represent the in situ rock mass quality. RQD calculation can be determined using equation1. Table 1 shows rock mass quality classification according to RQD.

$$
R Q D=\frac{\sum \text { lenqth of core pieces }>10 \mathrm{~cm}}{\text { total lenqth of the core }}
$$

Table 1

Rock mass classification based on RQD

\begin{tabular}{l|l|l}
\hline 1 & Rock Quality Designation & RGD \\
\hline A & Very Poor & $0-25$ \\
\hline B & Poor & $25-50$ \\
\hline C & Fair & $50-75$ \\
\hline D & Good & $75-90$ \\
\hline E & Exellent & $90-100$ \\
\hline
\end{tabular}

When no cores are available, RQD can be estimated from Joint spacing [22].

Rock Mass Rating (RMR) System or the Geomechanics Classification was developed by Bieniawski during 1972-1973 in South Africa to assess the stability and support requirements of tunnels [14]. Since then it has been successively refined and improved as more case histories have been examined. 
The uniaxial compressive strength of the intact rock $(\sigma c)$ : for rocks of moderate to high strength, point load index is also acceptable [15].

Rock Quality Designation (RQD)

Discontinuity spacing

Condition of discontinuity surfaces

Groundwater conditions

Orientation of discontinuities relative to the engineered structure It does not include in-situ stress conditions.

Bieniawski [16] has developed the following correlation between the $Q$-index and the

$\mathrm{RMR}$ in the form of a semi-log equation given by;

$$
R M R=9 \log Q+A
$$

Where $A$ varies between 26 and 62, and the average of $\mathrm{A}$ is 44 (derived from 111 case histories in tunneling).

Rock Tunneling Quality Index ( $Q$-System) was developed in 1974 by Barton, Lien, and Lunde at the Norwegian Geotechnical Institute, Norway for the determination of rock mass characteristics and tunnel support requirements [17], [18]. RMR and $Q$-Systems use essentially the same approach but different log-scale ratings, as $Q$ value is the product of the ratio of parameters while RMR is the sum of parameters [19]. The $Q$-rating is developed by assigning values to six parameters that are grouped into three quotients. The numerical value of the index $Q$ ranges from 0.001 to a maximum of 1,000 on a logarithmic scale [15]. Value of Q is defined and is calculated as

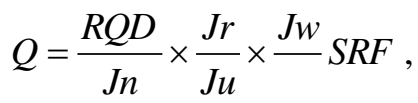

where $R Q D$ (Rock quality designation)>10 (measuring the

$R Q D$ (Rock quality designation) > 10 (measuring the degree of fracturing);

$J n$, Joint set number (number of discontinuity sets);

$J r$, Joint roughness number for critically oriented joint set (roughness of discontinuity surfaces);

$J u$, Joint alteration number for critically oriented joint set (degree of alteration or weathering and filling of discontinuity surfaces);

$J w$, Joint water reduction number (pressure and inflow rates of water within discontinuities); 
$S R F$, Stress reduction factor (presence of shear zones, stress concentrations, squeezing or swelling rocks).

\section{Mining practices}

Ore extraction in underground mines involves the generation of different type of excavations. The standup time of different types of ore source hereby referred to as stopes depend on the methods of extract and the duration of active ore extraction. The particular method chosen for the exploitation of an orebody is determined by such factors as its size, shape and geometric disposition, the distribution of values within the orebody, and the geotechnical environment [20]. Irrespective of the mining technique adopted for ore extraction are four common rock mechanics which are:

(a) To ensure the overall stability of the complete mine structure,

(b) To protect the major service openings throughout their designed duty life;

(c) To provide secure access to safe working places in and around the centres of ore

Production; and to $(d)$ to preserve the mineable condition of unmined ore reserves [20]

\section{Mining sequence}

Mining sequence must be designed by taking into account long term benefits and not short term factors because capital recovery is a long process. Practice of not following the mining sequence may, result in the creation of high stress blocks within the orebody. Kalunga and Mutambo [21] applied numerical modelling using PHASE2 software at $985 \mathrm{~mL}, 2110 \mathrm{mN}$ stope to evaluate stope hanging wall behaviour. They found that in most cases the stope hangingwall are located in a zone of relaxation or low tensile induced stress. The relaxation zones leads to unclamping of the key blocks and subsequent failure of some stopes. Additionally, poor ground conditions as well as poor drilling and blasting practices are precursor to ground failures. This position is supported by [22] reported that when a fractured rock mass is in a relaxed state stress zone, the rock blocks separated by discontinuities and the opening walls can unravel. Hangingwall sloughage occurs when the confinement of the minor principle stress is below or equal to zero [23]. When induced stress is higher than the shear strength of the rock mass around the stope, localized failures will occur following discontinuities or direct 
through intact rock resulting into [24]. According to Villaescusa, [24] the larger the stope opening the larger the more deformations that are expected at the stope walls hence making the walls more prone to damage due to blasting or stress redistribution. The magnitude and orientation of the in situ stresses greatly influences the relaxation zone [25. For instance, for similar geometries, the greater the stress regime is, the deeper the relaxation zone extends into the surrounding rock mass [25]. Henning and Mitri [23] proposed that the zone of stress relaxation reduces the clamping forces which are supposed to prevent sloughing or unravelling of the stope walls. The behaviour of stope walls is dependent on the strength of the surrounding rock mass which also depend on the geometrical nature and strength of the geological discontinuities and rock material [24]. Hughes [22], points out that rock mechanics properties such as strength of the rockmass and geological characteristics such as RQD, joint structures all influence the stability of stope walls. Therefore, the stability of underground excavations must be assessed d by taking into account geotechnical environment and the standup time for the excavation.

This study was undertaken to investigate the causes and effects of mining induced subsidence at Lubambe copper mine and provide mitigation mechanisms for reducing the likeliness of re-occurrence of undetected subsidence. Application of these mitigation factors will also allow the mine to prepare for contingency plans in an event of re-occurrence of subsidence, thereby reducing the impact on daily production, the surrounding infrastructure and the nearby community.

\section{Materials and Methods}

Underground physical inspections were conducted regularly for Geotechnical assessment of the ground condition, mining practices (mining sequence, stoping and firing) and the hydrogeology of the mine. During these inspections scanline and window mapping was conducted to determine the dip, dip direction and persistence of discontinuities in all the ramps across the mine. The mapping data was entered in the mapping database in Microsoft office excel and analysed using dips, Unwedge and RS3 software. Some of the instrumentation used to conduct these inspections and assessments includ- 
ed; flash light, distometer, geological compass, measuring tape, geological hammer, note book, clip board and pens.

On surface, core logging was done from the core yard where raw data was logged onto the logging sheets in intervals of $1 \mathrm{~m}$. Once logging of an entire bore hole was completed, the logged data was then entered into the core logging data base in Microsoft excel for empirical and numerical geotechnical analysis and interpretation using (Bieniawski's and Barton) rock mass classification criteria and GEM 4D software respectively. Extensive literature review was done on the geotechnical data available onsite which included; core logging and mapping databases, ground control management plan (GCMP), consultancy reports and, online review of published papers written on mining induced subsidence and other scholars literature in mining pertaining to this case study.

\section{Results and discussion}

Results of the study indicate that, the first subsidence occurrence on the east limb resulted in development of three sink holes. From the geotechnical analysis conducted using the empirical and numerical approach, it was discovered that the east limb sinkholes developed after a catastrophic failure was recorded underground at R3_182 mL decline which affected a lateral stretch of approximately $50 \mathrm{~m}$. Figures 1-6 show the stress analysis from $113 \mathrm{ml}$ to $182 \mathrm{ml}$.

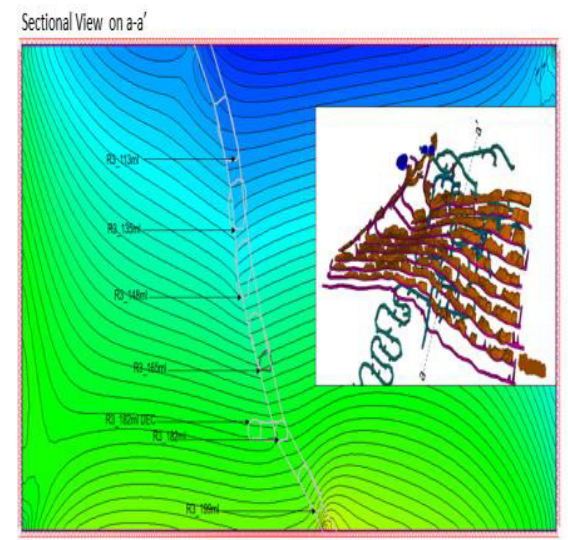

Fig. 1. Pre-mining insitu stress state (Phase 1) 


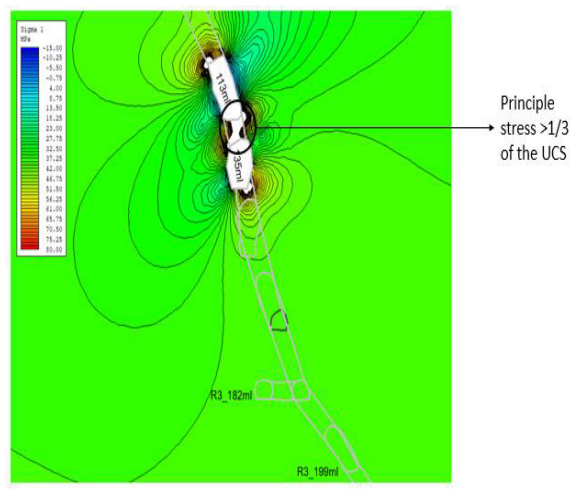

Fig. 2. Mining $113 \mathrm{ml}$ and $135 \mathrm{ml}$ (Phase 2)

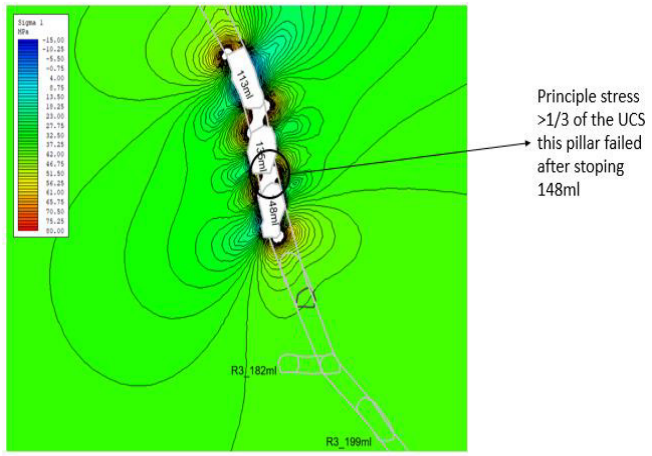

Fig. 3. Mining $135 \mathrm{ml}$ and $148 \mathrm{ml}$ (Phase 3)

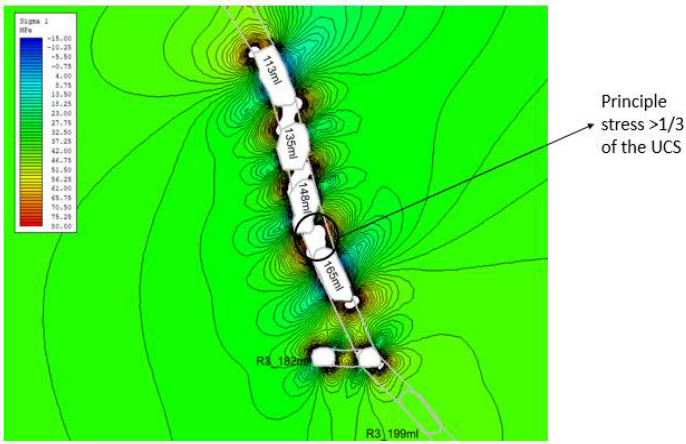

Fig. 4. Mining $148 \mathrm{ml}$ and $165 \mathrm{ml}$ (Phase 4) 


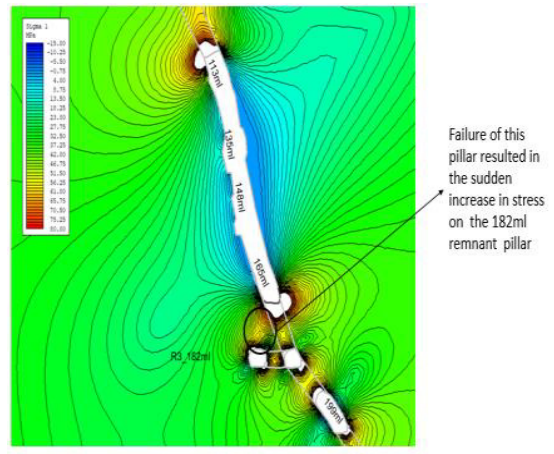

Fig. 5. Mining $182 \mathrm{ml}$ (Phase 5)

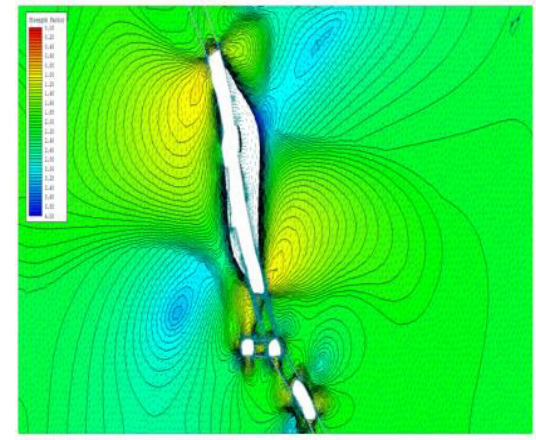

Fig. 6. Strength factor variation at $182 \mathrm{ml}$ Decline

From the numerical model done it was interpreted that, failure of the decline underground was

Caused by the following reasons listed below;

Stopes from $113 \mathrm{ml}$ to $182 \mathrm{ml}$ were designed to hole with $4 \mathrm{~m}$ sill/chain pillars. The design check shows that the minimum sill pillar should have been at least $5 \mathrm{~m}$ and the stopes should not have been designed to hole into each other.

The stope spans on $165 \mathrm{ml}$ were designed at approximately $74 \mathrm{~m}$ - $120 \mathrm{~m}$ long, and in cases where the rib pillar failed the stopes were $126 \mathrm{~m}$ long. This approach gave a very low factor of safety on the regional stability of this level with respect to $148 \mathrm{ml}$ the above.

The decline proximity analysis indicates that the location of the decline was designed within the stress redistribution zone with respect to the $182 \mathrm{ml}$ wrecking stope. The middling between the de- 
cline and $182 \mathrm{~mL}$ ore drive was approximately $6-7 \mathrm{~m}$ which was not sufficient for a $5 \times 5$ excavation. The effect on the excavation is as a result of induced stress acting perpendicular to the principle stress direction damaging the top and bottom shoulder of the drive.

The sinkholes on surface are as a result of the sill pillar failures on $165 \mathrm{ml}$ cascading through to $148 \mathrm{ml}, 135 \mathrm{ml}$ hereby creating hanging wall instability as the ground unravels to fill the voids.

On the southern limb the first two sink holes also developed as a result of subsidence, this occurred after a blast was conducted underground at R2_325 mL and a fall of ground in R2_372 mL respectively. So far, a total of three sinkholes have been recorded on the south limb bringing the total number of sink holes across the mine to six. Aside production related factors the additional factor that contributed to the expedition of subsidence on the south limb was the ponding water that was caused by uncontrolled leakages and the lowest point on the hanging wall were rain water accumulated in the wet season hereby highly saturating the area.

Table 2 shows the rock mass classification of the ground condition from the south and east limbs separately based on equation 1 .

Table 2

Shows the rock mass classification of the ground condition

\begin{tabular}{|c|c|c|c|}
\hline Year & Rock Type & Ramp & RQD \\
\hline $2018-2021$ & Arkose & 1 & $33 \%$ \\
\hline $2018-2021$ & Shale & 1 & $30 \%$ \\
\hline $2018-2021$ & Conglomerate & 1 & $25 \%$ \\
\hline \multicolumn{3}{|c|}{ Average } & $30 \%$ \\
\hline $2018-2021$ & Arkose & 2 & $31 \%$ \\
\hline $2018-2021$ & Shale & 2 & $28 \%$ \\
\hline $2018-2021$ & Conglomerate & 2 & $26 \%$ \\
\hline \multicolumn{3}{|c|}{ Average } & $29 \%$ \\
\hline $2018-2021$ & Arkose & 3 & $36 \%$ \\
\hline $2018-2021$ & Shale & 3 & $38 \%$ \\
\hline $2018-2021$ & Conglomerate & 3 & $39 \%$ \\
\hline \multicolumn{3}{|c|}{ Average } & $40 \%$ \\
\hline $2018-2021$ & Arkose & 4 & $36 \%$ \\
\hline $2018-2021$ & Shale & 4 & $38 \%$ \\
\hline $2018-2021$ & Conglomerate & 4 & $39 \%$ \\
\hline \multicolumn{3}{|c|}{ Average } & $44 \%$ \\
\hline $2018-2021$ & Arkose & 5 & $48 \%$ \\
\hline $2018-2021$ & Shale & 5 & $38 \%$ \\
\hline $2018-2021$ & Conglomerate & 5 & $52 \%$ \\
\hline \multicolumn{3}{|c|}{ Average } & $45 \%$ \\
\hline
\end{tabular}


Empirical analysis of the core logged data for rock mass classification using the RMR,Q-system and RQD results showed that the ground condition on the south and east limb can be classified as poor to fair ground as shown in Table 3.

Table 3

Empirical analysis of the core logged data for rock mass classification using the RMR, Q- system and RQD

\begin{tabular}{cccc}
\hline Limb & Criteria & Value & Classification \\
\hline South & RQD & $29.2 \%$ & Poor \\
South & RMR & $46.7 \%$ & Fair \\
South & Q-System & 2 & Poor \\
& & & \\
East & RQD & $43 \%$ & Poor \\
East & RMR & $51.2 \%$ & Fair \\
East & Q-System & 7.3 & Fair \\
\hline
\end{tabular}

The subsidence that resulted into sink hole development on both limbs can be mainly attributed to historical and current mining operations. From the historical data available it shows that the mining method practiced was a non-supported method which left behind open stopes. Information from historical mining conducted in the $1950 \mathrm{~s}$ shows production at Lubambe started on the southern limb at $100 \mathrm{~mL}$, some of their stopes were as close as $54 \mathrm{~m}$ from surface. With stopes this close to surface accompanied by an open stoping method and large stopes in weathered ground due to mining at shallow depth caving/subsidence is bound to occur.

The current mining method employed is a variant of room and pillar 'modified room and pillar' which also falls under open stoping methods(unsupported underground mining methods).This method has stope designs of $20-25 \mathrm{~m}$ with $6 \mathrm{~m}$ rib pillars and $5 \mathrm{~m}$ sill pillars that are not designed to hole.

The mining sequence of modified room and pillar is as follows;

The excavation is mined to completion for ore development with primary support installed.

\section{Thereafter secondary support is installed.}

Production drilling commences

And, lastly stoping is conducted.

The firing sequence used has the following sequence;

Ring 1 is fired 
Rings 2 and 3 are taken together

Ring 4 to the last ring in the panel are fired in a mass blast.

This firing sequence is adopted for the whole mine but subject to change upon geotechnical recommendation if there are ground condition issues in the area.

The average water discharged from underground on a monthly basis for the year 2021 was $300,000 \mathrm{~m}^{3}$ which translates to $10,000 \mathrm{~m}^{3} /$ day. The water bearing rock or aquifer is the conglomerate also known as the "kafufya' which lies on the footwall side of the ore body. Most of the water pumped from underground is from the eastern limb which comprises of Ramps 3,4 and 5. Most of the water from the east limb comes from a neighbouring mine in DRC which is currently flooded and has no operations taking place. Operations have gone deeper than this mine therefore the water accumulating from this flooded mine is seeping into Lubambe development as they mine deeper hereby dewatering the flood from the neighbouring mine.

On the southern limb, there isn't much water and can be described as fairly dry because Konkola copper mine in Chililabombwe has dewatered most of the water in the levels Lubambe is currently mining from due to the fact that $\mathrm{KCM}$ operations are way deeper than that of Lubambe.

\section{Conclusion}

This study sought to investigate the causes and effects of mining induced subsidence at Lubambe copper mine. From the investigations done, the major cause of mining induced subsidence at Lubambe can be attributed to historical and current mining operations. The historical and current mining method employed at the mine falls under non-supported underground methods which leaves open stopes behind upon completion of stoping. The current method allows for development to be completed followed by production drilling and stoping, the stoping sequence starts from the limit of the ore drive retreating towards the level access.

Subsidence due to sinkhole formation has had profound effects on both mining operations and community infrastructure such as the road and water pipelines in close proximity to the cave line. This has resulted in additional costs due to re-routing of the water pipes, construction of emergency road to the mine and community and construction of a new tarred road. 


\section{Recommendation}

In addition to INSAR satellite monitoring system the mine should consider installing surface and underground movement monitoring instrumentation. Currently the only instruments in use underground are roctails which have not been placed in all active excavations.

\section{Acknowledgement}

The authors would like to thank Lubambe mine for providing valuable data for this study. We would also like to extend our thanks to the Dean, School of Mines at the University of Zambia for providing logistical support in form of transport to and from the mine site.

\section{Funding Source}

This study was not funded by any external supporters, all the costs associated with the study were covered by the principle investigator of the study.

Potential conflict

There is no potential conflict of interest.

\section{References}

1. Longwe, P. (2020). Draft - Lubambe Ground Control Management Plan. Copperbelt, Zambia: Un-Published.

2. Nestbitt, A., 2003. Subsidence Monitoring West Cliff Colliery Longwall 5A4, APAS (Association of Public Authority Surveyors) 2003 Conference, Wollongong, Australia, 1-4.

3. Schofield, W., 1993. Engineering Surveying, Laxton's, Oxford, UK, 554pp

4. Zhang, Z., Wang, C., Tang, Y., Fu, Q., Zhang, H., 2015. Subsidence monitoring in coal area using time-series insar combining persistent scatterers and distributed scatterers. Int.J. Appl. Earth Obs. Geoinf. 39, 49-55. https://doi.org/10.1016/j.jag.2015.02.007.

5. Carnec, C., Massonnet, D., and King, C. (1996). Two Examples of the Use of SAR Interferometry on Displacement fields of Small Spatial Extent. Geophys. Res. Lett. 23, 3579-3582. doi:10.1029/96GL03042

6. Carnec and Delacourt, (20000. Three years of mining subsidence monitored by SAR interferometry, near Gardanne, France. DOI:10.1016/S09269851(99)00032-4 Corpus ID: 15825685

7. Baek, J., Kim, S.W., Park, H.J., Jung, H.S., Kim, K.D., Kim, J.W., 2008. Analysis of ground subsidence in coal mining area using sar interferometry. Geosci. J. $12,277-284$.

8. https://doi.org/10.1007/s12303-008-0028-3

9. Yu, H. W., Lan, Y., Yuan, Z. H., Xu, J. Y., and Lee, H. (2019). Phase Unwrapping in InSAR : A Review. IEEE Geosci. Remote Sens. Mag. 7, 40-58. doi:10.1109/MGRS.2018.2873644 
10. Madsen and Zebker (1992. Automated Absolute Phase Retrieval in AcrossTrack Interferometry. DOI:10.1109/IGARSS.1992.578639. Corpus ID: 62291773

11. Zebker, H.A., Villasenor, J., 1992. Decorrelation in interferometric radar echoes. IEEE Trans. Geosci. Remote Sens. 30, 950-959. https://doi.org/10.1109/36.175330.

12. Raucoules, D., Ristori, B., De Michele, M., Briole, P., 2010. Surface displacement of the mw 7 machaze earthquake (mozambique): complementary use of multiband insar and radar amplitude image correlation with elastic modelling. Remote Sens. Environ.114, 2211-2218. https://doi.org/10.1016/j.rse.2010.04.023

13. Huang, J., Deng, K., Fan, H., Yan, S., 2016. An improved pixel-tracking method for monitoring mining subsidence. Remote Sens. Lett. 7, 731-740. https://doi.org/10.1080/2150704x.2016.1183177

14. Zhao, C., Lu, Z., Zhang, Q., 2013. Time-series deformation monitoring over mining regions with sar intensity-based offset measurements. Remote Sens. Lett. 4, 436-445.https://doi.org/10.1080/2150704X.2012.746482.

15. Bieniawski, Z.T., 1993, Classification of rock masses for engineering: The RMR system and future trends, In: Hudson, J.A., ed., Comprehensive Rock Engineering, Volume 3: Oxford; New York, Pergamon Press, p. 553-573.

16. Bieniawski, Z.T., 1989, Engineering rock mass classifications: a complete manual for engineers and geologists in mining, civil, and petroleum engineering: New York, Wiley, xii, 251 Pp..

17. Bieniawski, Z.T., 1976, Rock Mass Classification in Rock Engineering, in Bieniawski, Z.T., ed., Symposium on exploration for rock engineering, Balkema: Rotterdam, p. 97-106.

18. Barton, N.R., R. Lien and J. Lunde, 1974. Engineering classification of rock masses for the design of tunnel support. Rock Mech., 6: 189-239. DOI: 10.1007/BF01239496

19. Barton, N., 1988, Rock mass classification and tunnel reinforcement selection using the Q-System, Rock classification for engineering purpose, Volume 984: ASTM Special Technical Publication: Philadelphia, p. 59-88.

20. E. Hoek (2007). Rock mass properties Practical rock, engineering.w.rocscience.com/learning/hoek-s-corner

21. Brady B.H.G and Brown E.T (1985). Rock Mechanics for underground ground Mining. London. Chapman and Hall. ISNB: 0-412-475-50-2

22. Kalunga Ngoma, Victor Mutambo (2020). Factors Influencing Ore Recovery and Unplanned Dilution in Sublevel Open Stopes. Case Study of Shaft No.4 at Konkola Mine, Zambia. World Current Journal, Special Issue on Mining. Pp 3446 DOI: http://dx.doi.org/10.12944/CWE15

23. Hughes, R., 2011. Factors influencing overbreak in narrow vein longitudinal retreat mining, s.1.: Mc.Gill University.

24. Henning, J, and Mitri, H, 2007. Mine Planning for Ore dilution Villaescusa, E. 1995. Sources of external dilution in underground sublevel and bench stoping, Procc. AusIMM Explo Conference, Brisbane Australia, pp 217-223

25. Clark, L. M., 1998. Minimizing dilution in open stope mining with a focus on stope design and narrow vein longhole blasting. MSc. Thesis, University of British Columbia. 